\title{
3D-Membrane Stacks on Supported Membranes Composed of Diatom Lipids Induced by Long-chain Polyamines
}

\author{
Oliver Gräb ${ }^{1}$, Maryna Abacilar ${ }^{2}$, Fabian Daus $^{2}$, Armin Geyer $^{2}$, Claudia Steinem $^{1 *}$ \\ ${ }^{1}$ University of Göttingen, Institute of Organic and Biomolecular Chemistry, Tammannstr. 2, \\ 37077 Göttingen, Germany, ${ }^{2}$ Philipps-University Marburg, Faculty of Chemistry, Hans- \\ Meerwein-Str. 4, 35032 Marburg, Germany
}

\section{SILANIZED SUBSTRATES}

Cover slides (D $263 \mathrm{M}$ Schott glass, ibidi GmbH, Munich, DE) were cut into quadratic pieces $\left(6 \times 6 \mathrm{~mm}^{2}\right)$ and fixed with UV curing glue onto glass slides. After rinsing with detergent solution (Hellmanex, Hellma Analytics, Müllheim, DE) and ultrapure water $(2 \times)$, for 15 min each, the slides were dried under vacuum at $90{ }^{\circ} \mathrm{C}$ for $2 \mathrm{~h}$. Afterwards, the cover slides were covered with hexamethyldisilazane (HMDS, $20 \mu \mathrm{L}$ ) and the liquid was allowed to evaporate over night at room temperature. The surface was characterized by atomic force microscopy (AFM) and contact angle measurements before and after addition of HMDS. AFM measurements were performed in air using intermittent contact mode on a MFP-3D AFM (Asylum Research, Santa Barbara, US) and OMCL-AC160TS-R3 cantilevers (resonant frequency (air) $280.5-340.3 \mathrm{kHz}$, spring constant $31.7-36.9 \mathrm{~N} \cdot \mathrm{m}^{-1}$, Olympus, Tokyo, JP). Contact angles were measured by adding $2 \mu \mathrm{L}$ of ultrapure water onto the surface. Contact angles were determined from photographs of the droplets using the Image $^{1}$ plugin Drop Shape Analysis. $^{2,3}$

HMDS reacts with hydrophilic glass surfaces by binding of trimethylated silanes to hydroxyl groups of the glass under release of ammonia resulting in an increase of hydrophobicity of the surface. ${ }^{4}$ The surface topography before and after functionalization was measured by AFM. Topographic maps of both substrates show plan surfaces with a roughness of 1-2 nm with some additional larger structures on top with an average height of about $10 \mathrm{~nm}$ (Fig. S1). Contact angle measurements provide solid evidence that the surface is rendered hydrophobic after HDMS functionalization. A contact angle of about $28^{\circ}$ was found for the unmodified glass surface (hydrophilic surface), while the angle increases to $84^{\circ}$ after HDMS addition (hydrophobic surface). Addition of small unilamellar vesicles to hydrophobic surfaces leads to the deposition of lipid monolayers. ${ }^{5}$ 

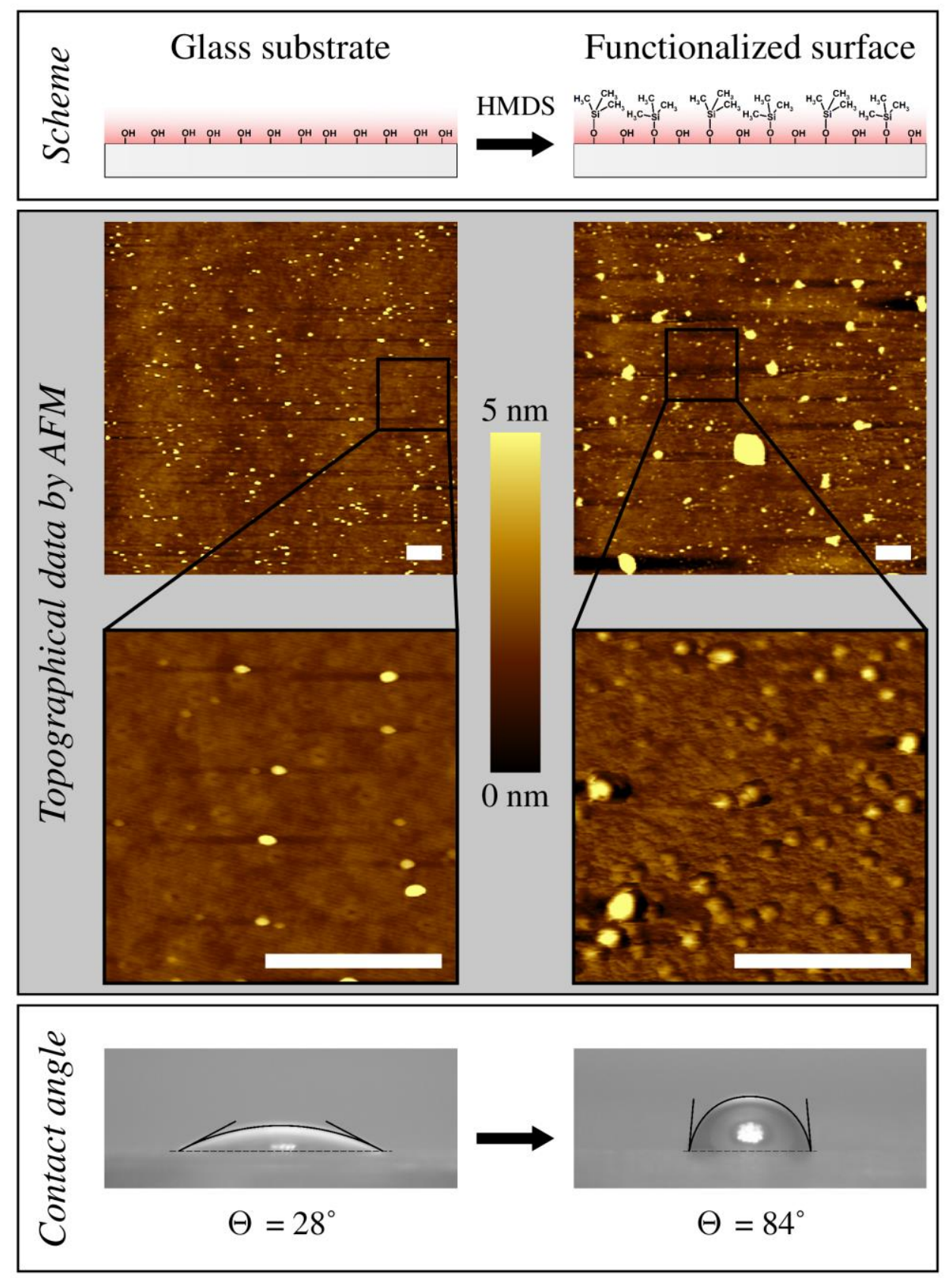

Fig. S1. Hydrophobic functionalization of glass substrates. Trimethylated silanes bind to hydroxyl groups on the glass surface upon addition of HMDS. The topography of the surface before (left) and after (right) functionalization was visualized by AFM showing only minor changes due to HMDS addition (scale bars: $500 \mathrm{~nm}$ ). Water contact angles on the surfaces increased from $28^{\circ}$ to $84^{\circ}$ demonstrating the increased hydrophobicity after HDMS functionalization.

\section{C3N13 ADSORPTION ON MEMBRANE SURFACES}

Adsorption of C3N13 on membrane surfaces was quantified by reflectometric interference spectroscopy (RIfS) in order to determine its binding constant and identify a LCPA concentration that ensures close to maximum surface coverage for all following experiments. 
A custom-build setup was employed using a NanoCalc 2000 spectrometer (Ocean Optics Germany GmbH, Ostfildern, DE). ${ }^{6}$ Sample preparation was carried out on silicon wafers with a layer of $5 \mu \mathrm{m}$ silicon dioxide. The surfaces were hydrophilized by an aqueous solution of $\mathrm{NH}_{3}$ and $\mathrm{H}_{2} \mathrm{O}_{2}\left(\mathrm{H}_{2} \mathrm{O} / 25 \% \quad \mathrm{NH}_{3} / 30 \% \mathrm{H}_{2} \mathrm{O}_{2} \quad 5: 1: 1 \mathrm{v} / \mathrm{v} / \mathrm{v}\right)$ at $70{ }^{\circ} \mathrm{C}$ for $20 \mathrm{~min}$ followed by a $30 \mathrm{~s}$ treatment with oxygen plasma (Zepto, Diener, Ebhausen, DE). Small unilamellar vesicles (MGDG/DGDG/SQDG/POPG/DOPC, 35:20:15:5:25, $0.1 \mathrm{mg} \cdot \mathrm{mL}^{-1}$ ) were added in citrate buffer $\left(50 \mathrm{mM} \mathrm{KCl}, 20 \mathrm{mM}\right.$ trisodium citrate/HCl, $0.1 \mathrm{mM}$ EDTA, $0.1 \mathrm{mM} \mathrm{NaN}_{3}, \mathrm{pH} 4.8$ ) followed by rinsing with acetate buffer ( $50 \mathrm{mM} \mathrm{KCl}, 40 \mathrm{mM} \mathrm{NaOAc} / \mathrm{HOAc}, \mathrm{pH}$ 5.5). C3N13 was added in acetate buffer until a stable change in optical thickness $(\triangle O T)$ was observed. After rinsing with acetate buffer the LCPA concentration was increased.

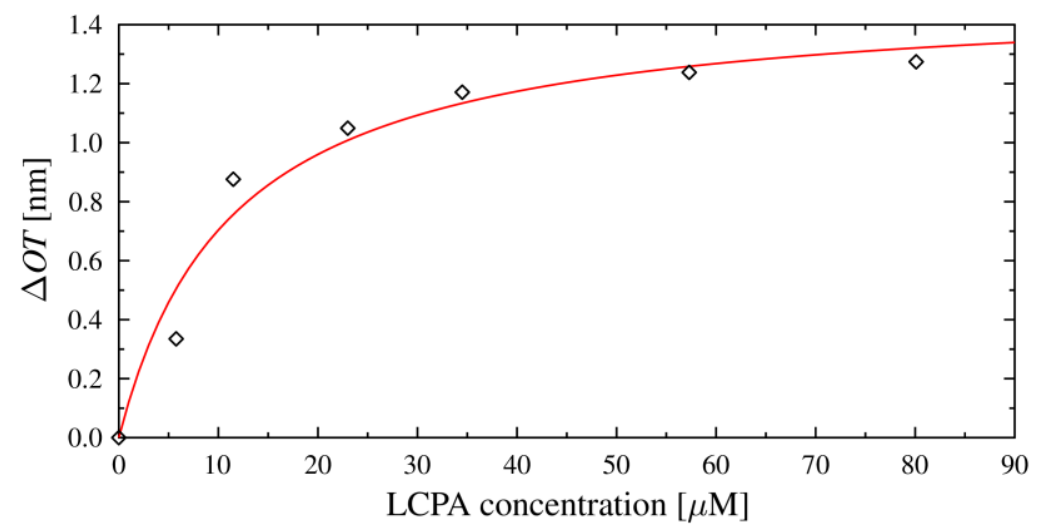

Fig. S2. Changes in optical thickness $(\triangle O T)$ observed by RIfS after addition of C3N13 to a membrane coated $\mathrm{Si} / \mathrm{SiO}_{2}$ surface. The LCPA concentration is given with respect to the number of nitrogen atoms in the molecule. A concentration of $c_{\mathrm{N}}=30 \mu \mathrm{M}$ ensures a near maximum surface coverage.

\section{References}

(1) Abramoff, M. D.; Magalhães, P. J.; Ram, S. J. Image processing with ImageJ. Biophotonics intern. 2004, 11, $36-42$.

(2) Stalder, A. F.; Melchior, T.; Müller, M.; Sage, D.; Blu, T.; Unser, M. Low-bond axisymmetric drop shape analysis for surface tension and contact angle measurements of sessile drops. Colloids Surf. A 2010, 364, 7281.

(3) Stalder, A. F.; Kulik, G.; Sage, D.; Barbieri, L.; Hoffmann, P. A snake-based approach to accurate determination of both contact points and contact angles. Colloids Surf. A 2006, 286, 92-103.

(4) Bauer, J.; Drescher, G.; Illig, M. Surface tension, adhesion and wetting of materials for photolithographic process. J. Vac. Sci. Technol. B 1996, 14, 2485-2492.

(5) Keller, C. A.; Kasemo, B. Surface specific kinetics of lipid vesicle adsorption measured with a quartz crystal microbalance. Biophys. J. 1998, 75, 1397-1402.

(6) Ludolphs, M.; Schneeberger, D.; Soykan, T.; Schäfer, J.; Papadopoulos, T.; Brose, N.; Schindelin, H.; Steinem, C. Specificity of collybistin-phosphoinositide interactions: Impact of the individual protein domains. J. Biol. Chem. 2016, 291, 244-254. 